This is an author produced version of a paper published in The International Journal of Biochemistry \& Cell Biology. This paper has been peer-reviewed but does not include the final publisher proof-corrections or journal pagination.

Citation for the published paper:

Takao, Koichi and Rickhag, Mattias and Hegardt, Cecilia and Oredsson, Stina and Persson, Lo "Induction of apoptotic cell death by putrescine."

Int J Biochem Cell Biol. 2006;38(4):621-8. http://dx.doi.org/10.1016/j.biocel.2005.10.020.

Access to the published version may require journal subscription. Published with permission from: Elsevier 


\title{
Induction of apoptotic cell death by putrescine
}

\author{
Koichi Takao ${ }^{\mathrm{a}, 1}$, Mattias Rickhag ${ }^{\mathrm{a}, \mathrm{b}}$, Cecilia Hegardt ${ }^{\mathrm{b}, \mathrm{c}}$, \\ Stina Oredsson ${ }^{\mathrm{b}}$ and Lo Persson, ${ }^{\mathrm{a},{ }^{*}}$
}
${ }^{\mathrm{a}}$ Department of Experimental Medical Science, Lund University, S-22184 Lund, Sweden
${ }^{b}$ Department of Cell and Organism Biology, Lund University, S-22362 Lund, Sweden 'Department of Clinical Sciences, Lund University, S-22185 Lund, Sweden

Running Header: Putrescine and apoptosis

\author{
${ }^{1}$ Present address: Laboratory of Cellular Physiology \\ Department of Clinical Dietetics \& Human Nutrition \\ Faculty of Pharmaceutical Sciences \\ Josai University \\ Sakado \\ Saitama 350-0295 \\ Japan \\ *Corresponding author \\ Department of Experimental Medical Science \\ BMC F-13, S-221 84 Lund, Sweden \\ Phone: $46-46-2227746$ \\ FAX: $\quad 46-46-2224546$ \\ e-mail: lo.persson@med.lu.se
}




\begin{abstract}
The polyamines are essential for cellular growth and differentiation. Ornithine decarboxylase (ODC), which catalyses the first step in the biosynthesis of the polyamines, has a very fast turnover and is subject to a strong feedback control by the polyamines. In the present study we show that overexpression of a metabolically stable ODC in CHO cells induced a massive cell death unless the cells were grown in the presence of the ODC inhibitor $\alpha$ difluoromethylornithine (DFMO). Cells overexpressing wild-type (unstable) ODC, on the other hand, were not dependent on the presence of DFMO for their growth. The induction of cell death was correlated with a dramatic increase in cellular putrescine levels. Analysis using flow cytometry revealed perturbed cell cycle kinetics, with a large accumulation of cells with sub- $\mathrm{G}_{1}$ amounts of DNA, which is a typical sign of apoptosis. Another strong indication of apoptosis was the finding that one of the key enzymes in the apoptotic process, caspase-3, was induced when DFMO was omitted from the growth medium. Furthermore, inhibition of the caspase activity significantly reduced the recruitment of cells to the sub- $\mathrm{G}_{1}$ fraction. In conclusion, deregulation of polyamine homeostasis may negatively affect cell proliferation and eventually lead to cell death by apoptosis if putrescine levels become too high.
\end{abstract}

Key words: Polyamines; ornithine decarboxylase; apoptosis; protein turnover; caspase-3 


\section{Introduction}

The polyamines putrescine, spermidine and spermine are cellular constituents shown to be essential for a variety of cell processes related to growth and differentiation (Heby and Persson 1990; Jänne et al. 2004; Wallace et al. 2003). Mammalian intracellular levels of the polyamines are under a strong regulatory control, reflecting their importance in cell physiology. Too low concentrations of cellular polyamines may negatively affect anabolic events such as DNA, RNA and protein syntheses, eventually inducing cell growth arrest (Wallace et al. 2003). Too high concentrations of the polyamines, on the other hand, are toxic to the cell and may induce cell death (Brunton et al. 1990; Poulin et al. 1995; Tome et al. 1997). Thus it is important for cells to maintain their polyamine concentrations within rather narrow limits.

Polyamine homeostasis is achieved by a careful balance between synthesis, degradation and uptake (Casero, Jr. and Pegg 1993; Coffino 2001; Heby and Persson 1990). All these events are highly regulated and subjected to feedback control by the polyamines. Ornithine decarboxylase (ODC) (EC 4.1.1.17), which catalyses the first step in polyamine synthesis, has a very fast turnover and is highly regulated by the intracellular polyamine levels (Coffino 2001; Hayashi et al. 1996; Murakami et al. 2000). In the presence of an excess of polyamines, there is a marked down-regulation of cellular ODC activity. On the other hand, when cells are depleted of their polyamines ODC is markedly induced. The major effect of the polyamines is on the level of ODC turnover, although some effect on ODC mRNA translation has also been demonstrated (Persson et al. 1996). The polyamines exert their effect on ODC turnover by inducing the synthesis of a protein, antizyme, which binds to the ODC monomer and targets it for degradation by the 26S proteasome (Coffino 2001; Hayashi et al. 1996; Murakami et al. 2000). 
The C-terminal part of mammalian ODC has been shown to be very important for the fast turnover of the enzyme (Ghoda et al. 1989; Rosenberg-Hasson et al. 1991). Truncations or mutations in this part of ODC transform the enzyme into a metabolically stable protein. The binding of antizyme to ODC is believed to affect the structure of the protein in such a way that the C-terminal part of ODC is exposed, which then is recognized by the $26 \mathrm{~S}$ proteasome (Coffino 2001; Hayashi et al. 1996).

The mechanisms by which too high intracellular polyamine levels may induce cell death are not known yet. Interestingly, a few reports exist in which such cell death is shown to be caused by apoptosis (Poulin et al. 1995; Tobias and Kahana 1995; Tome et al. 1997; Xie et al. 1997). However, in some cases the cell death appears to be non-apoptotic (Seiler et al. 2000). In the present study we have used a cell line overproducing a C-terminus truncated ODC, which is metabolically stable and thus non-responsive to the feedback control exerted by the polyamines, to examine the effects of deregulation of polyamine synthesis on cell viability. It is demonstrated that deregulation of ODC causes an induction of apoptosis, which can be reduced by the addition of the caspase inhibitor Z-VAD-fmk. The induction of apoptosis is most likely related to the massive increase in putrescine content in the cells caused by the deregulation of ODC. 


\section{Materials and Methods}

\subsection{Materials}

Caspase-3 Colorimetric Protease Assay kit and $N$-Benzyloxycarbonyl-Val-Ala-Aspfluoromethylketone (Z-VAD-fmk) were purchased from Medical \& Biological Laboratories Co., Ltd. (Nagoya, Japan). AlamarBlue ${ }^{\mathrm{TM}}$ was purchased from BioSource (Camarillo, CA, USA).

\subsection{Cell culture}

Wild-type $\mathrm{CHO}$ cells and stable transfectants of $\mathrm{CHO}$ cells expressing a C-terminally truncated ODC were made resistant to $5 \mathrm{mM} \alpha$-difluoromethylornithine (DFMO) as described in Lövkvist Wallström et al. 2001. The cells (CHO-D and CHO- $\triangle 3-\mathrm{D})$ were routinely grown in Dulbecco's minimum essential medium/Ham's F12 (1:1) containing 10\% fetal calf serum, nonessential amino acids, antibiotics (50 units/ml penicillin and $50 \mu \mathrm{g} / \mathrm{ml}$ streptomycin) and 1-5 mM DFMO. The cells were cultured at $37^{\circ} \mathrm{C}$ in a humidified incubator with $5 \% \mathrm{CO}_{2}$ and subcultured at a density of $10-20 \times 10^{3}$ cells $/ \mathrm{cm}^{2}$ every 3 or 4 days. Cell proliferation was determined by cell counting or by means of a reduction-oxidation assay using the metabolic indicator resazurin in AlamarBlue.

\subsection{AlamarBlue assay}

Cells were seeded in the absence or presence of various concentrations of DFMO in 96well plates at a density of 25,000 cells/well. The plates were incubated at $37^{\circ} \mathrm{C}$ for $1-4$ days, 
whereupon $20 \mu$ AlamarBlue (10\%) was added to each well. The plates were incubated for an additional $4 \mathrm{~h}$ and then the fluorescence was determined at $544 \mathrm{~nm}$ excitation and $590 \mathrm{~nm}$ emission. Blank values were obtained from wells without cells. Resazurin in AlamarBlue is reduced to a fluorescent product by cells and the degree of reduction corresponds to the number of viable cells.

\subsection{Polyamine analysis}

Cells grown in the absence or presence of $5 \mathrm{mM}$ DFMO for various times were harvested and stored at $-20{ }^{\circ} \mathrm{C}$ until analysed. Chromatographic separation and quantitative determination of the polyamines in $0.2 \mathrm{M}$ perchloric acid extracts of the cells were carried out using high performance liquid chromatography (HP 1100) essentially as described in Seiler and Knödgen 1980.

\subsection{Flow cytometric analysis}

Cells were resuspended in ice-cold $70 \%$ ethanol and then stored at $-20{ }^{\circ} \mathrm{C}$ until analysed. Nuclei were isolated and DNA was stained with propidium iodide nuclear isolation medium (phosphate-buffered saline containing $100 \mu \mathrm{g} / \mathrm{ml}$ propidium iodide, $0.60 \%$ Nonidet P-40 and $100 \mu \mathrm{g} / \mathrm{ml}$ RNase A) (Hegardt et al. 2001). Flow cytometric analysis was performed in an Ortho Cytoron Absolute flow cytometer (Ortho Raritan, NJ) as previously described (Fredlund et al. 1994). For computerised analysis of cell cycle phase distributions, Multi2D and MultiCycle software programs (Phoenix Flow Systems, CA) were used. When present, sub- $\mathrm{G}_{1}$ peaks were calculated as percentage of the total DNA histogram. 


\subsection{Analysis of caspase-3 activity}

Cells $\left(1-2 \times 10^{6}\right)$ grown in the absence or presence of $1 \mathrm{mM}$ DFMO for 72 or $78 \mathrm{~h}$ were harvested and stored in $50 \mu \mathrm{l}$ of cell lysis buffer at $-80{ }^{\circ} \mathrm{C}$ until analysed. The caspase activity was assayed by measuring the cleavage of the chromophore $p$-nitroanilide $(p \mathrm{NA})$ from a $p$ NA-labelled substrate according to the manufacturer's instructions. The samples were incubated with $200 \mu \mathrm{M} p \mathrm{NA}$ substrate at $37^{\circ} \mathrm{C}$ for $2 \mathrm{~h}$ before measurement of the absorbance at $405 \mathrm{~nm}$.

\subsection{Statistical analysis}

Values are expressed as mean \pm S.D. Student's $t$-test was used for statistical evaluation and $\mathrm{p}<0.05$ was considered as significant.

\section{Results}

The CHO- $\Delta 3-\mathrm{D}$ cells, which express large amounts of a metabolically stable (Cterminally truncated) ODC (Lövkvist Wallström et al. 2001), were capable of growing in the presence of $5 \mathrm{mM}$ DFMO (Fig. 1). However, omission of DFMO from the growth medium induced a growth arrest followed by a dramatic reduction in cell number starting 3 days after seeding (Fig. 1). As comparison a cell line of wild-type CHO cells resistant to the same level of DFMO (CHO-D) (Lövkvist Wallström et al. 2001) were used. As seen in Fig. 1, these cells 
grew equally well in the absence and presence of $5 \mathrm{mM}$ DFMO. No reduction in cell number was seen during day 3 and 4 after seeding in a medium without DFMO.

The omission of DFMO from the growth medium gave rise to a large increase in cellular ODC activity (results not shown). The increase in ODC activity was reflected in an increase in putrescine content of the cells (Fig. 2). In the CHO-D cells the putrescine content rose to a peak level by day 2 when grown without DFMO. This level was more than 25 times higher than the putrescine level found in the same cells grown for 2 days in the presence of 5 mM DFMO $(\mathrm{p}<0.05)$. The putrescine level of the CHO- $\Delta 3-\mathrm{D}$ cells increased to a very high level when the cells were grown without DFMO (Fig. 2). The peak levels, which were found 3 days after seeding, were more than 200-fold higher than in the CHO- $\Delta 3-\mathrm{D}$ cells grown in the presence of DFMO ( $\mathrm{p}<0.001)$, and almost 10-fold higher than the putrescine content of the CHO-D cells grown without DFMO $(\mathrm{p}<0.001)$. The putrescine content of the CHO- $\triangle 3-\mathrm{D}$ cells grown without DFMO was lower on day 4 compared to day 3 (Fig. 2). This corresponded in time with the marked reduction in cell number seen when the CHO- $\Delta 3-\mathrm{D}$ cells were grown in the absence of DFMO.

During exponential growth (day 1-3) the CHO- $\Delta 3-\mathrm{D}$ appeared to contain slightly less spermidine than the CHO-D cells when grown in the presence of $5 \mathrm{mM}$ DFMO (Fig. 2). However, when the cells were grown without DFMO both cell lines exhibited a transient increase in spermidine content compared to the cells grown in the presence of DFMO. For the CHO-D cells this increase appeared on day 1 and was about 1.6 -fold $(\mathrm{p}<0.01)$, whereas for the $\mathrm{CHO}-\Delta 3-\mathrm{D}$ cells the spermidine content was increased both on days $1(2.0$-fold, $\mathrm{p}<0.01)$ and 2 (3.7-fold, $\mathrm{p}<0.001$ ) (Fig. 2). However, during day 4 there was a significant decrease in the spermidine content in both cells lines $(\mathrm{p}<0.01)$ when grown in the absence of DFMO compared to the cells grown in the presence of DFMO (Fig.2). The spermine concentration, 
on the other hand, was markedly decreased in both cell lines during day $2-4(\mathrm{p}<0.001-0.05)$, when DFMO was omitted from the growth medium (Fig. 2).

To determine whether the death of CHO- $\Delta 3-\mathrm{D}$ cells occurring 3-4 days after growth in the absence of DFMO may be related to the huge increase in putrescine content we did a titration of the effects of various DFMO concentrations on cell growth and putrescine content. Cell growth was analysed by a sensitive fluorescent assay using the reagent AlamarBlue. Surprisingly, there was an increase $(\mathrm{p}<0.001)$ in the amount of fluorescence (cell number) when the CHO- $\triangle 3$-D cells were grown in concentrations of $0.75-1.5 \mathrm{mM}$ DFMO compared to $5 \mathrm{mM}$ DFMO (Fig. 3A). This may indicate that the cells were not completely resistant to the higher concentration of DFMO. Thus, $1 \mathrm{mM}$ DFMO was selected as the optimal concentration for growth of the CHO- $\Delta 3-\mathrm{D}$ cells. The adverse effects on cell growth caused by reduction of DFMO in the growth medium was apparent on day 4 when concentrations of $0.5 \mathrm{mM}$ DFMO and lower was used $(\mathrm{p}<0.01)$ (Fig. 3). Concentrations of $0.1 \mathrm{mM}$ or less gave a reduction in cell growth also on day 3 (results not shown). The putrescine contents of the cells grown in the presence of $0-1 \mathrm{mM}$ DFMO are shown in Fig. 4. As seen in this figure the putrescine content was very high in the cells grown in the presence of $0.1 \mathrm{mM}$ DFMO or less compared to the cells grown in the presence of $1 \mathrm{mM}$ DFMO. The levels appeared higher on day 4 than on day 3 (Fig. 4).

Next, we analysed the cell cycle phase distribution among the CHO- $\Delta 3-\mathrm{D}$ cells grown in the presence of 0-1 mM DFMO (Fig. 5). A major difference found was that the cells grown in the presence of $1 \mathrm{mM}$ DFMO accumulated in the $\mathrm{G}_{1}$-phase (Fig. 5B), whereas the cells grown in $0.1 \mathrm{mM}$ DFMO or less accumulated in the $\mathrm{S}$ - and $\mathrm{G}_{2}$-phases (Fig. 5C-D), with a decrease in the $\mathrm{G}_{1}$ phase 3-4 days after seeding (Fig. 5B). Another striking observation was that a large fraction of the cells seeded in the presence of $0.1 \mathrm{mM}$ DFMO or less contained reduced DNA content $\left(\right.$ sub- $\left.\mathrm{G}_{1}\right)$ on days $3(\mathrm{p}<0.001-0.05)$ and $4(\mathrm{p}<0.001)$ (Fig. 5A). The 
number of cells in the sub- $\mathrm{G}_{1}$ fraction increased between day 3 and 4 when cells were grown in $0.1 \mathrm{mM}$ DFMO or less. More than $50 \%$ of the cells grown in the absence of DFMO, whereas less than $7 \%$ of the cells grown in the presence of $1 \mathrm{mM}$ DFMO was found in the sub- $\mathrm{G}_{1}$ fraction 4 days after seeding (Fig. 5A).

Accumulation of cells in the sub- $\mathrm{G}_{1}$ fraction is often a result of cells undergoing apoptotic cell death (Darzynkiewicz et al. 1992). The appearance of cells in the sub- $\mathrm{G}_{1}$ fraction in the present study coincided with the inhibition of cell growth and later cell death occurring 3-4 days after seeding the cells in absence or in the presence of low concentrations of DFMO. In order to analyse whether apoptosis may be induced, we measured the activity of caspase-3, which is generally activated by all major apoptotic signal transduction pathways (Kaufmann and Earnshaw 2000), in cells grown in the absence or presence of $1 \mathrm{mM}$ DFMO for 72 and 78 h. As shown in Fig. 6A, there was a significant increase $(p<0.01)$ in the caspase3 activity in the cells grown without DFMO. Treatment of cells seeded in the absence of DFMO with $1 \mu \mathrm{M}$ Z-VAD-fmk, a broad-spectrum caspase inhibitor (Graczyk 2002), reduced the number of cells found in the sub- $\mathrm{G}_{1}$ fraction (from $51 \%$ to $34 \%, \mathrm{p}<0.001$ ) 4 days after seeding (Fig. 6B). However, cells grown in the presence of both $1 \mu \mathrm{M} \mathrm{Z-VAD-fmk} \mathrm{and} 1 \mathrm{mM}$ DFMO showed an increased number (from $2 \%$ to $21 \%, \mathrm{p}<0.01$ ) of cells in the sub-G1 fraction on day 4 (Fig. 6B).

\section{Discussion}

The deletion of the C-terminus of ODC transforms the protein from a metabolically unstable protein into a stable protein with a very slow turnover (Ghoda et al. 1989). The 
extensive regulation of ODC is highly dependent on the very fast turnover of the protein (Coffino 2001; Hayashi et al. 1996; Murakami et al. 2000). Any change in synthesis or degradation of ODC is rapidly causing a change in the amount of protein, and thus in activity, of the enzyme. Hence, cells expressing the wild-type ODC are capable of rapidly responding to a disturbance of polyamine homeostasis by adjusting the ODC level accordingly. Cells expressing a C-terminally truncated ODC, on the other hand, may not respond as effective due to the very slow turnover of the enzyme. In the present study we have demonstrated the importance of the ODC turnover for the cellular response to a disturbed polyamine homeostasis. The cells used were expressing ODC to very high levels and were routinely grown in the presence of DFMO. Thus, only a fraction of the ODC protein was enzymatically active. However, omitting DFMO from the growth medium should result in a loss of enzyme inactivation and, if unregulated, in a massive increase in ODC activity and putrescine synthesis. In the cells expressing wild-type ODC there was an increase in putrescine content when the cells were grown without DFMO. However, this was minor compared to the huge increase in putrescine content found when the cells expressing the c-terminally truncated ODC were seeded in a medium without DFMO. The cellular putrescine reached levels that were 1 to 2 orders of magnitude greater than those normally found in wild-type CHO cells (Fredlund and Oredsson 1997).

The putrescine levels obtained in the cells expressing the C-terminally truncated ODC when these were seeded in the absence of DFMO appeared to be highly toxic to the cells. The growth arrest and later cell death observed from day 3 coincided with the huge increase in putrescine content. Furthermore, results from titration with DFMO supported a connection between supra-physiological putrescine levels and growth arrest/cell death. Analysis of cell cycle phase distribution revealed major differences between the cells grown in the absence or presence of DFMO. When grown in $1 \mathrm{mM}$ DFMO, which inhibited most of the ODC activity, 
the cells exhibited normal cell cycle phase distributions. During exponential growth, most of the cells were found in the $G_{1}$ and $S$ phases, whereas the number of cells in the $G_{2}$ phase remained relatively low. When the cells were approaching confluency (day 4) there was an accumulation of cells in the $G_{1}$ phase, and to a lesser extent also in the $G_{2}$ phase. The number of cells in the S phase, on the other hand, decreased markedly by day 4. Cells grown in the absence of DFMO, or in low DFMO concentrations, showed instead a marked decrease in the number of cells in the $\mathrm{G}_{1}$ phase during days 3-4 and no decrease in the number of cells in the $\mathrm{S}$ phase at confluency. The number of cells in the $\mathrm{G}_{2}$ phase was higher in the cells grown in the absence of DFMO, or in low DFMO concentrations, than found in the cells grown in the presence of $1 \mathrm{mM}$ DFMO. Concomitant with the decrease in number of cells in the $\mathrm{G}_{1}$ phase, occurring after seeding the cells in the absence or in the presence of low concentrations of DFMO, there was a huge increase of cells (up to 50-60\%) containing reduced amount of DNA $\left(\mathrm{sub}-\mathrm{G}_{1}\right)$, which is a common feature of cells undergoing apoptotic cell death (Darzynkiewicz et al. 1992). The number of cells in the sub- $\mathrm{G}_{1}$ fraction was relatively small when the cells were grown in the presence of $1 \mathrm{mM}$ DFMO. Interestingly, $0.1 \mathrm{mM}$ DFMO gave an intermediate value (about $30 \%$ ) on the number of cells in the sub- $\mathrm{G}_{1}$ fraction. This concentration of DFMO did also give rise to lower cellular putrescine levels than in the cells grown in the absence or presence of $0.04 \mathrm{mM}$ DFMO (which gave $50-60 \%$ sub- $\mathrm{G}_{1}$ cells), but still much higher putrescine levels than in the cells grown in the presence of $1 \mathrm{mM}$ DFMO. Thus, elevation of cellular putrescine content seems to contribute to the commitment of cells to the sub- $\mathrm{G}_{1}$ fraction. The increased number of cells within the sub- $\mathrm{G}_{1}$ fraction appeared concomitant with the reduction of total cell number, indicating that cells were dying by an apoptotic process. Since the percentage of cells in the $\mathrm{G}_{1}$ phase decreased simultaneously, it is conceivable that a large number of the cells found in the sub- $\mathrm{G}_{1}$ fraction were derived from the $\mathrm{G}_{1}$ phase. The finding that the percentage of cells in the $\mathrm{S}$ phase did not change indicated 
that also cells from this cell cycle phase were recruited to the sub- $\mathrm{G}_{1}$ fraction. Otherwise the percentage of cells in the S phase should increase due to the decrease in total number of cells.

The presence of a large number of cells in the sub- $\mathrm{G}_{1}$ fraction strongly indicated that the reduction in cell number seen when cells were grown in the absence, or in the presence of low concentrations, of DFMO was due to apoptotic cell death. This was supported by the finding that there was an induction of caspase- 3 activity in the cells at the time when the changes in cell cycle phase distribution became apparent. Furthermore, treatment with the caspase inhibitor Z-VAD-fmk significantly reduced the recruitment of cells to the sub- $\mathrm{G}_{1}$ fraction. Interestingly, Z-VAD-fmk gave rise to an increase in the fraction of sub- $\mathrm{G}_{1}$ cells when given together with DFMO. The reason for this is not known. However, Z-VAD-fmk has been demonstrated to increase cell death in some systems (Cowburn et al. 2005; Paananen et al. 2005; Pandey et al. 2000).

Accumulation of excessive levels of polyamines, as well as of various polyamine analogues, have been shown to induce apoptosis in different cell lines (Chen et al. 2003; Fraser et al. 2002; Hu and Pegg 1997; Pignatti et al. 2004; Poulin et al. 1995; Schipper et al. 2000; Tobias and Kahana 1995; Tome et al. 1997; Xie et al. 1997). Putrescine has been capable of inducing apoptosis in some systems but not in others (Poulin et al. 1995; Tobias and Kahana 1995; Tome et al. 1997; Xie et al. 1997). The exact mechanism(s) that are involved in the induction of apoptosis by polyamines (or their analogues) are not known. The polyamines (and some of their analogues) strongly induce the degradation of polyamines, which is associated with $\mathrm{H}_{2} \mathrm{O}_{2}$ production (Casero, Jr. and Pegg 1993). It is possible that the polyamine-induced apoptosis is caused by an oxidative stress. This theory is supported by the finding that MDL 72,527, an inhibitor of cellular FAD-dependent polyamine oxidase, was capable of reducing the apoptotic cell death caused by different polyamine analogues (Ha et al. 1997; Hu and Pegg 1997). Putrescine, on the other hand, has never been shown to induce 
polyamine degradation. Nevertheless, Erez et al. (Erez et al. 2002) demonstrated that apoptosis caused by putrescine in a mouse myeloma cell line was inhibited by aminoguanidine, which is an inhibitor of copper-containing amine oxidases like diamine oxidase. Thus, it is conceivable that also the apoptosis induced by excessive putrescine accumulation is due to an oxidative stress caused by $\mathrm{H}_{2} \mathrm{O}_{2}$. However, aminoguanidine did not appear to inhibit the induction of apoptosis in the CHO- $\Delta 3-\mathrm{D}$ cells after omission of DFMO from the growth medium (preliminary results).

Two different activation pathways have been revealed for the apoptotic process, one mitochondrial (release of cytochrome $c$ ) and one membrane receptor (death receptor). The signalling pathways also includes cascades of different caspases (Kaufmann and Earnshaw 2000). As shown in the present study, as well as in studies using different polyamine analogues, apoptosis was associated with an induction of caspase-3, which is a common nominator for both of the activation pathways (Chen et al. 2003; Fraser et al. 2002; Hegardt et al. 2002). Furthermore, results indicate that polyamine-induced apoptosis occurs through the mitochondrial pathway (Chen et al. 2001; Chen et al. 2003). However, the exact steps involved in the signalling pathway leading to apoptosis by supra-physiological polyamine levels is for the main part still unknown. The present cell system may provide a useful tool for further studies of these mechanisms.

\section{Acknowledgements}

This study was supported by grants from COST 922, the Swedish Cancer Society (L.P and S.O) and the Swedish Research Council (S.O.). 


\section{Figure legends}

Fig. 1. Effect of DFMO withdrawal on growth of DFMO resistant CHO cells. Cells were grown in the absence or presence of $5 \mathrm{mM}$ DFMO for four days. CHO-D + DFMO, $\bullet$; CHOD without DFMO, o; CHO- $\triangle 3$-D + DFMO, $\nabla$; CHO- $\triangle 3$-D without DFMO, $\nabla$. Mean \pm S.D., $\mathrm{n}=5$ independent samples.

Fig. 2. Effect of DFMO withdrawal on polyamine content in DFMO resistant CHO cells. Cells were grown in the absence or presence of $5 \mathrm{mM}$ DFMO for four days. CHO-D + DFMO, •; CHO-D without DFMO, o; CHO- $\triangle 3-\mathrm{D}+\mathrm{DFMO}, \boldsymbol{\nabla}$; CHO- $\triangle 3-\mathrm{D}$ without DFMO, V. Mean \pm S.D., $\mathrm{n}=3$ independent samples (except for day $0, \mathrm{n}=2$ ).

Fig. 3. Effect of DFMO on growth of CHO- $\Delta 3-\mathrm{D}$ cells. The cells were seeded in 96-well plates in the absence or presence of various concentrations of DFMO (A: $0.1-5 \mathrm{mM}$; B: 0.01 $-0.1 \mathrm{mM}$ ). On day 4 the number of cells were analysed using AlamarBlue. Mean \pm S.D., $\mathrm{n}=$ 6 independent samples.

Fig. 4. Effect of DFMO on putrescine content in CHO- $\Delta 3-\mathrm{D}$ cells. The cells were seeded in the absence or presence of various concentrations of DFMO and analysed for putrescine content on days 1, 2, 3 and 4. Mean \pm S.D., $\mathrm{n}=3$ independent samples.

Fig. 5. Effect of DFMO on cell cycle phase distribution of CHO- $\Delta 3-\mathrm{D}$ cells. The cells were seeded in the absence or presence of various concentrations of DFMO and analysed by flow cytometry on days $1,2,3$ and 4 . A, Sub-G ${ }_{1} ; B, G_{1} ; C, S ; D, G_{2} .1 \mathrm{mM}$ DFMO, •; $0.1 \mathrm{mM}$ 
DFMO, ०; 0.04 mM DFMO, $\boldsymbol{\nabla}$; without DFMO, $\nabla$. Mean \pm S.D., $\mathrm{n}=3$ independent samples.

Fig. 6. A. Effect of DFMO withdrawal on caspase-3 activity in CHO- $\Delta 3-\mathrm{D}$ cells. The cells were seeded in the absence or presence of $1 \mathrm{mM}$ DFMO and analysed for caspase- 3 activity after 72 and 78 h. B. Effect of the general caspase inhibitor Z-VAD-fmk on the percentage of CHO- $\Delta 3-\mathrm{D}$ cells in the sub- $\mathrm{G}_{1}$ phase of the DNA histogram. The cells were seeded in the absence or presence of $1 \mathrm{mM}$ DFMO and/or $1 \mu \mathrm{M}$ Z-VAD-fmk and analysed by flow cytometry after 4 days. Mean \pm S.D., $\mathrm{n}=3$ independent samples. 


\section{References}

Brunton, V. G., Grant, M. H., \& Wallace, H. M. (1990). Spermine toxicity and glutathione depletion in BHK-21/C13 cells. Biochem. Pharmacol., 40, 1893-1900.

Casero, R. A., Jr. \& Pegg, A. E. (1993). Spermidine/spermine $\mathrm{N}^{1}$-acetyltransferase--The turning point in polyamine metabolism. FASEB J., 7, 653-661.

Chen, Y., Kramer, D. L., Diegelman, P., Vujcic, S., \& Porter, C. W. (2001). Apoptotic signaling in polyamine analogue-treated SK-MEL-28 human melanoma cells. Cancer Res., $61,6437-6444$

Chen, Y., Kramer, D. L., Li, F., \& Porter, C. W. (2003). Loss of inhibitor of apoptosis proteins as a determinant of polyamine analog-induced apoptosis in human melanoma cells. Oncogene, 22, 4964-4972.

Coffino, P. (2001). Regulation of cellular polyamines by antizyme. Nat. Rev. Mol. Cell Biol., $2,188-194$.

Cowburn, A. S., White, J. F., Deighton, J., Walmsley, S. R., \& Chilvers, E. R. (2005). zVAD-fmk augmentation of TNF alpha-stimulated neutrophil apoptosis is compound specific and does not involve the generation of reactive oxygen species. Blood, 105, 29702972. 
Darzynkiewicz, Z., Bruno, S., Del Bino, G., Gorczyca, W., Hotz, M. A., Lassota, P., \& Traganos, F. (1992). Features of apoptotic cells measured by flow cytometry. Cytometry, $13,795-808$.

Erez, O., Goldstaub, D., Friedman, J., \& Kahana, C. (2002). Putrescine activates oxidative stress dependent apoptotic death in ornithine decarboxylase overproducing mouse myeloma cells. Exp. Cell Res., 281, 148-156.

Fraser, A. V., Woster, P. M., \& Wallace, H. M. (2002). Induction of apoptosis in human leukaemic cells by IPENSpm, a novel polyamine analogue and anti-metabolite. Biochem. $J ., 367,307-312$.

Fredlund, J. O., Johansson, M., Baldetorp, B., \& Oredsson, S. M. (1994). Abnormal DNA synthesis in polyamine deficient cells revealed by bromodeoxyuridine-flow cytometry technique. Cell Prolif., 27, 243-256.

Fredlund, J. O. \& Oredsson, S. M. (1997). Ordered cell cycle phase perturbations in Chinese hamster ovary cells treated with an S-adenosylmethionine decarboxylase inhibitor. Eur. $J$. Biochem., 249, 232-238.

Ghoda, L., van Daalen Wetters, T., Macrae, M., Ascherman, D., \& Coffino, P. (1989). Prevention of rapid intracellular degradation of ODC by a carboxyl-terminal truncation. Science, 243, 1493-1495.

Graczyk, P. P. (2002). Caspase inhibitors as anti-inflammatory and antiapoptotic agents. Prog. Med. Chem., 39, 1-72. 
Ha, H. C., Woster, P. M., Yager, J. D., \& Casero, R. A., Jr. (1997). The role of polyamine catabolism in polyamine analogue-induced programmed cell death. Proc. Natl. Acad. Sci. USA, 94, 11557-11562.

Hayashi, S., Murakami, Y., \& Matsufuji, S. (1996). Ornithine decarboxylase antizyme: A novel type of regulatory protein. Trends Biochem. Sci., 21, 27-30.

Heby, O. \& Persson, L. (1990). Molecular genetics of polyamine synthesis in eukaryotic cells. Trends Biochem. Sci., 15, 153-158.

Hegardt, C., Andersson, G., \& Oredsson, S. M. (2001). Different roles of spermine in glucocorticoid- and Fas-induced apoptosis. Exp. Cell Res., 266, 333-341.

Hegardt, C., Johannsson, O. T., \& Oredsson, S. M. (2002). Rapid caspase-dependent cell death in cultured human breast cancer cells induced by the polyamine analogue N1,N11diethylnorspermine. Eur. J. Biochem., 269, 1033-1039.

Hu, R. H. \& Pegg, A. E. (1997). Rapid induction of apoptosis by deregulated uptake of polyamine analogues. Biochem. J., 328, 307-316.

Jänne, J., Alhonen, L., Pietilä, M., \& Keinänen, T. A. (2004). Genetic approaches to the cellular functions of polyamines in mammals. Eur. J. Biochem., 271, 877-894.

Kaufmann, S. H. \& Earnshaw, W. C. (2000). Induction of apoptosis by cancer chemotherapy. Exp. Cell Res., 256, 42-49. 
Lövkvist Wallström, E., Takao, K., Wendt, A., Vargiu, C., Yin, H., \& Persson, L. (2001). Importance of the 3' untranslated region of ornithine decarboxylase mRNA in the translational regulation of the enzyme. Biochem. J., 356, 627-634.

Murakami, Y., Matsufuji, S., Hayashi, S., Tanahashi, N., \& Tanaka, K. (2000). Degradation of ornithine decarboxylase by the 26S proteasome. Biochem. Biophys. Res. Commun., 267 , $1-6$.

Paananen, A., Jarvinen, K., Sareneva, T., Salkinoja-Salonen, M. S., Timonen, T., \& Holtta, E. (2005). Valinomycin-induced apoptosis of human NK cells is predominantly caspase independent. Toxicology, 212, 37-45.

Pandey, S., Smith, B., Walker, P. R., \& Sikorska, M. (2000). Caspase-dependent and independent cell death in rat hepatoma 5123tc cells. Apoptosis., 5, 265-275.

Persson, Svensson, \& Lövkvist Wallström (1996). Regulation of polyamine metabolism. In K. Nishioka (Ed.), Polyamines in cancer: basic mechanisms and clinical approaches (pp. 1943). Austin: R.G. Landes Company.

Pignatti, C., Tantini, B., Stefanelli, C., \& Flamigni, F. (2004). Signal transduction pathways linking polyamines to apoptosis. Amino. Acids, 27, 359-365.

Poulin, R., Pelletier, G., \& Pegg, A. E. (1995). Induction of apoptosis by excessive polyamine accumulation in ornithine decarboxylase-overproducing L1210 cells. Biochem. J., 311 , 723-727. 
Rosenberg-Hasson, Y., Bercovich, Z., \& Kahana, C. (1991). Characterization of sequences involved in mediating degradation of ornithine decarboxylase in cells and in reticulocyte lysate. Eur. J. Biochem., 196, 647-651.

Schipper, R. G., Penning, L. C., \& Verhofstad, A. A. (2000). Involvement of polyamines in apoptosis. Facts and controversies: effectors or protectors? Semin. Cancer Biol., 10, 55-68.

Seiler, N., Duranton, B., Gosse, F., \& Raul, F. (2000). Spermine cytotoxicity to human colon carcinoma-derived cells (CaCo-2). Cell Biol. Toxicol., 16, 117-130.

Seiler, N. \& Knödgen, B. (1980). High-performance liquid chromatographic procedure for the simultaneous determination of the natural polyamines and their monoacetyl derivatives. $J$. Chromatogr., 221, 227-235.

Tobias, K. E. \& Kahana, C. (1995). Exposure to ornithine results in excessive accumulation of putrescine and apoptotic cell death in ornithine decarboxylase overproducing mouse myeloma cells. Cell Growth Differ., 6, 1279-1285.

Tome, M. E., Fiser, S. M., Payne, C. M., \& Gerner, E. W. (1997). Excess putrescine accumulation inhibits the formation of modified eukaryotic initiation factor 5A (eIF-5A) and induces apoptosis. Biochem. J., 328, 847-854.

Wallace, H. M., Fraser, A. V., \& Hughes, A. (2003). A perspective of polyamine metabolism. Biochem. J., 376, 1-14. 
Xie, X. Z., Tome, M. E., \& Gerner, E. W. (1997). Loss of intracellular putrescine pool-size regulation induces apoptosis. Exp. Cell Res., 230, 386-392. 


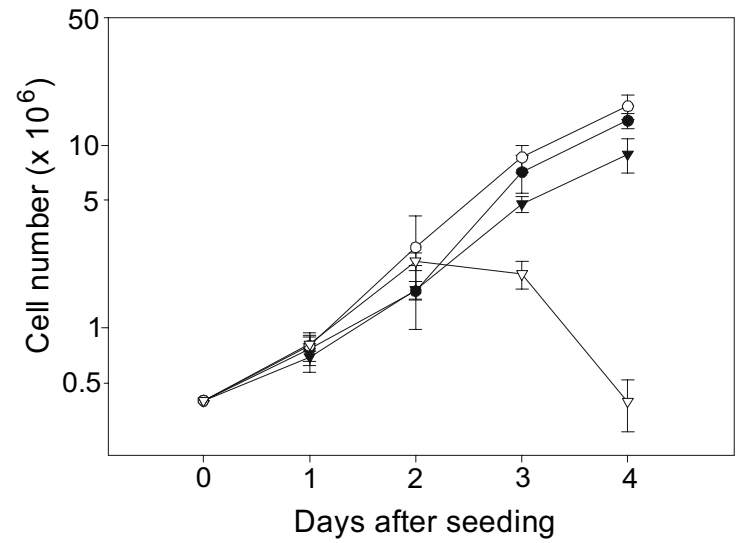

Fig.1 

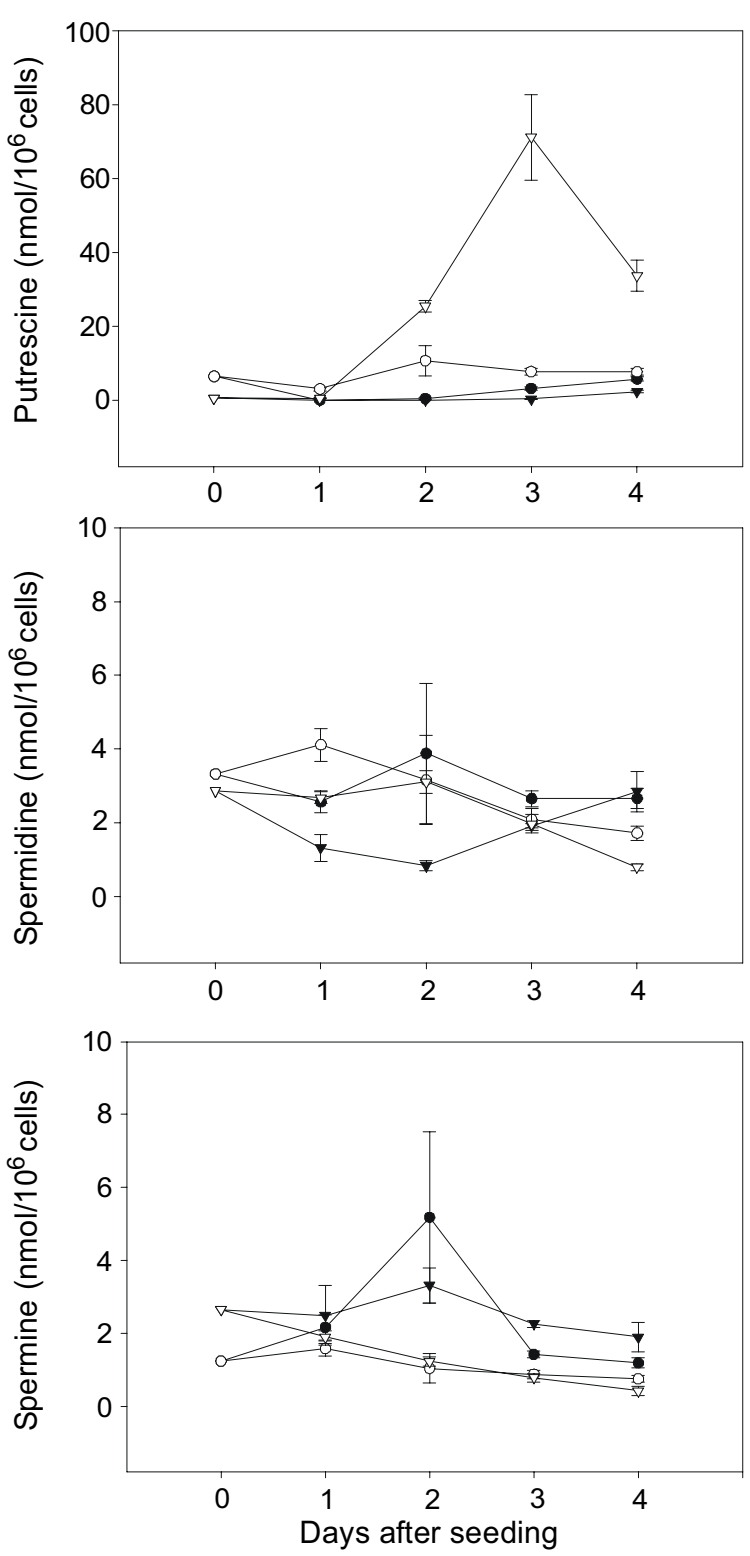

Fig. 2 

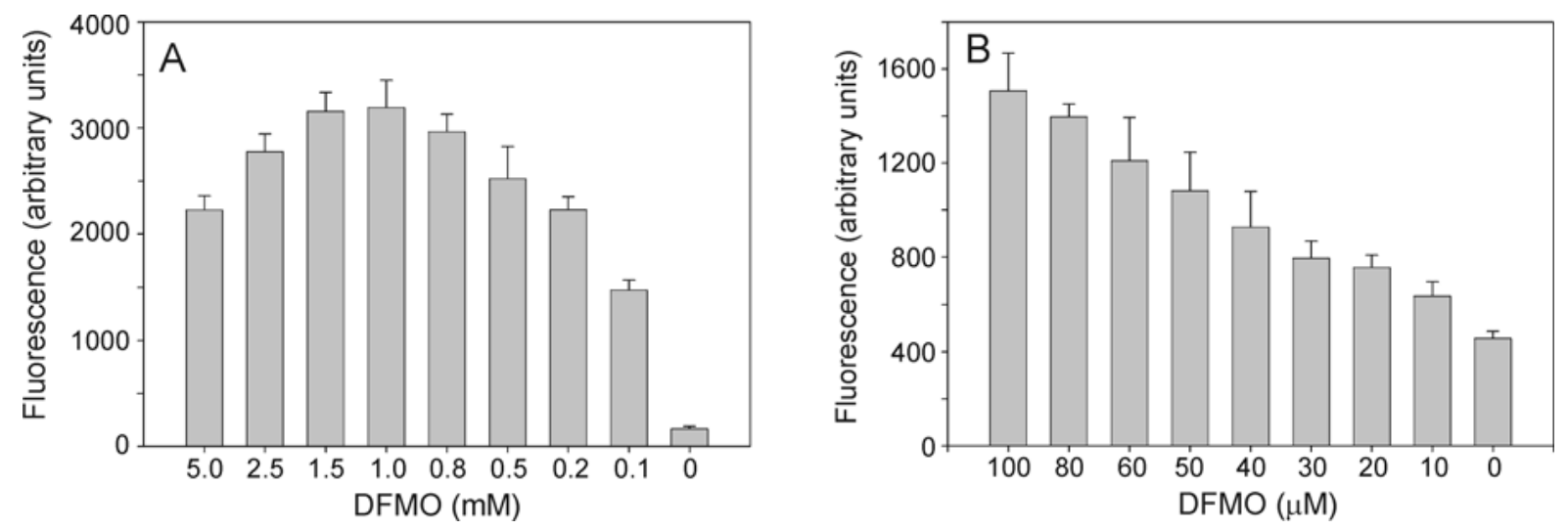

Fig. 3 


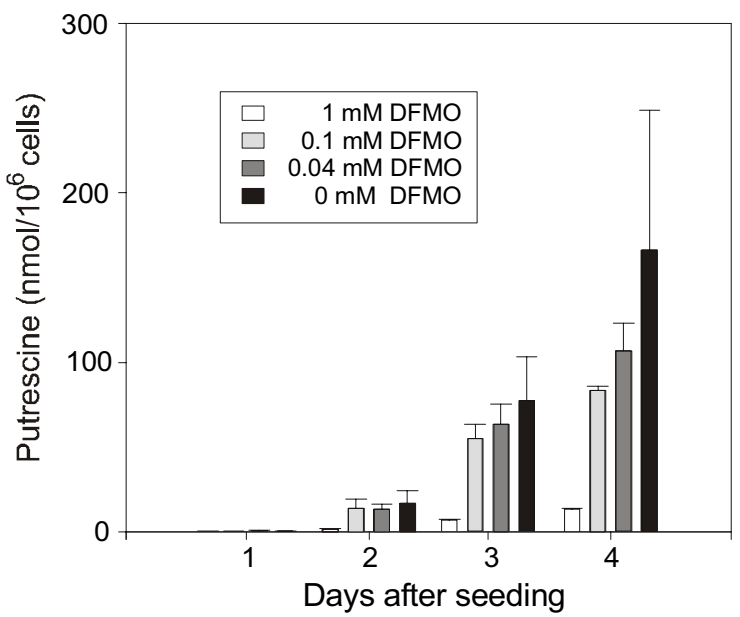

Fig. 4 

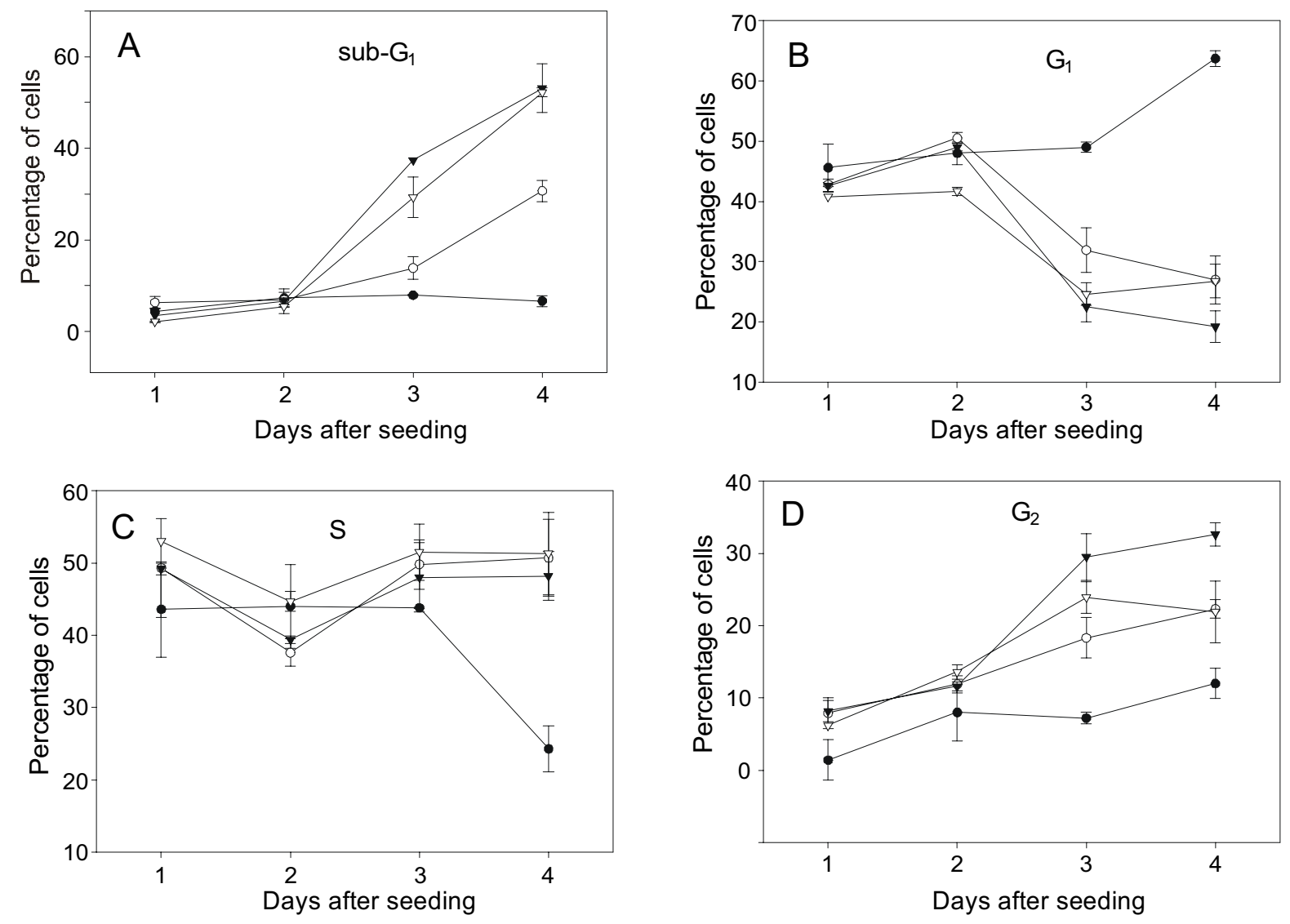

Fig. 5 

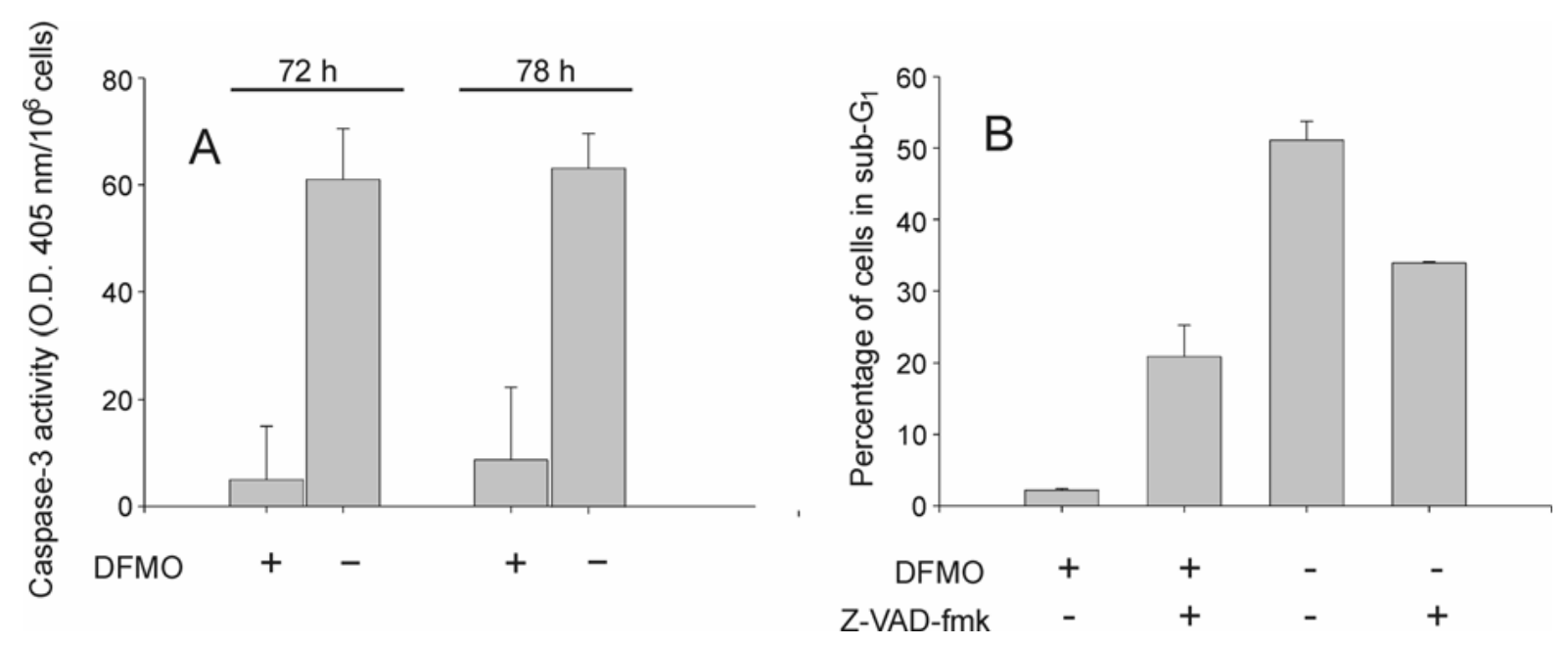

Fig. 6 